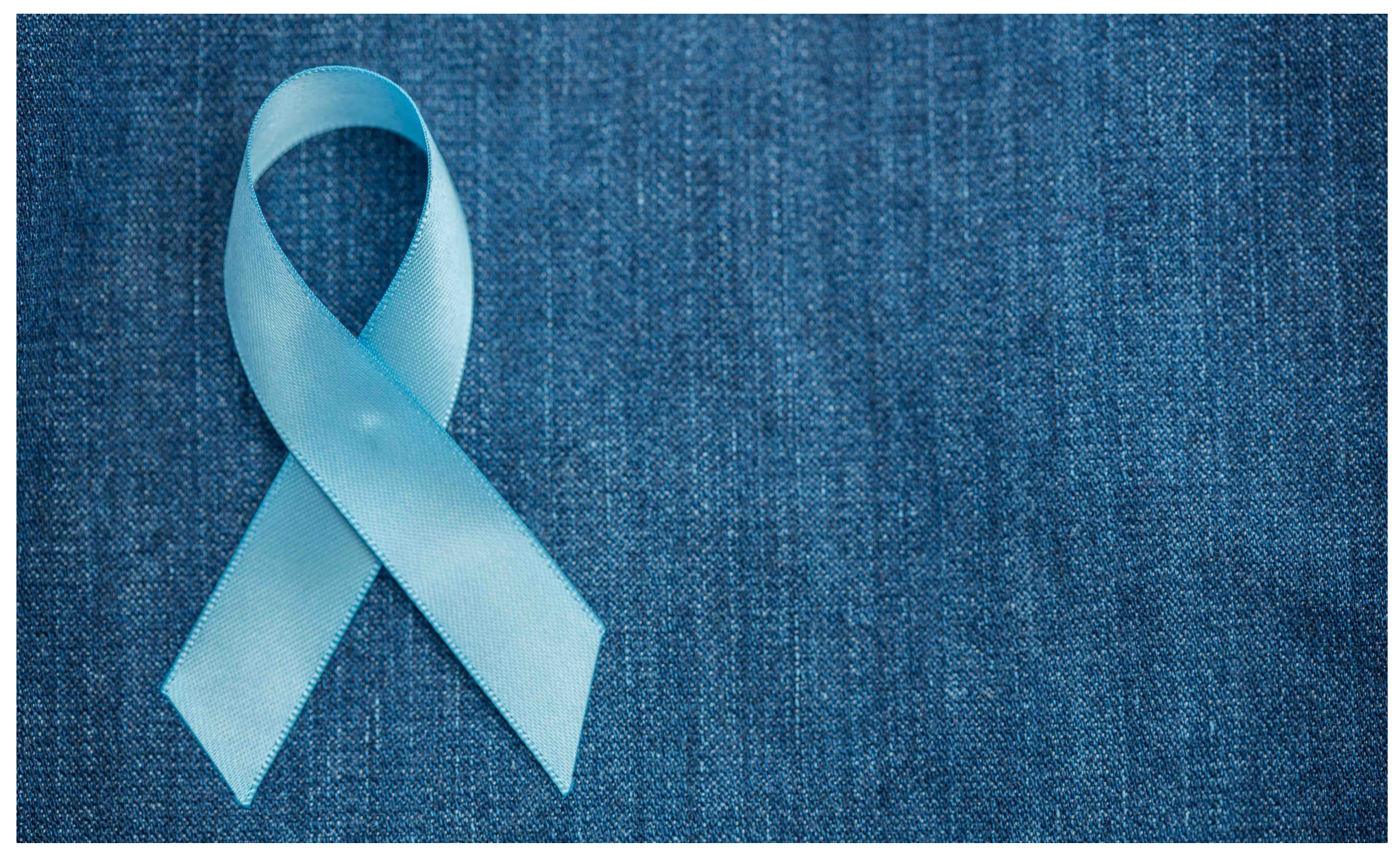

Artwork

\title{
Anatomy of the Male Reproductive System - Prostate Cancer
}

Lisa Xuan

Published online: 06 July 2017

${ }^{1}$ Faculty of Medicine, University of Ottawa, Ottawa, Canada

Corresponding Author: Lisa Xuan. 


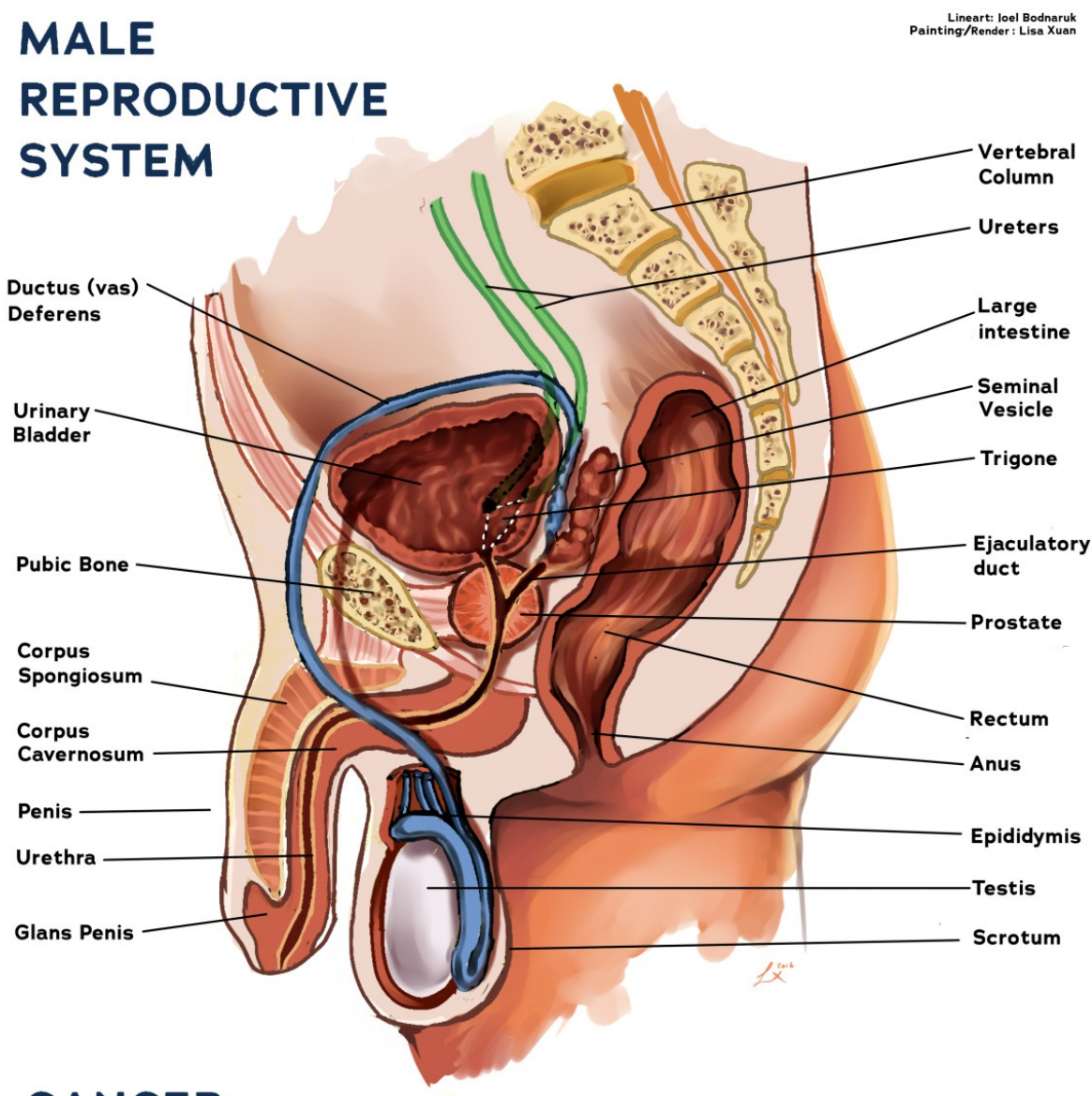

CANCER PROGRESSION

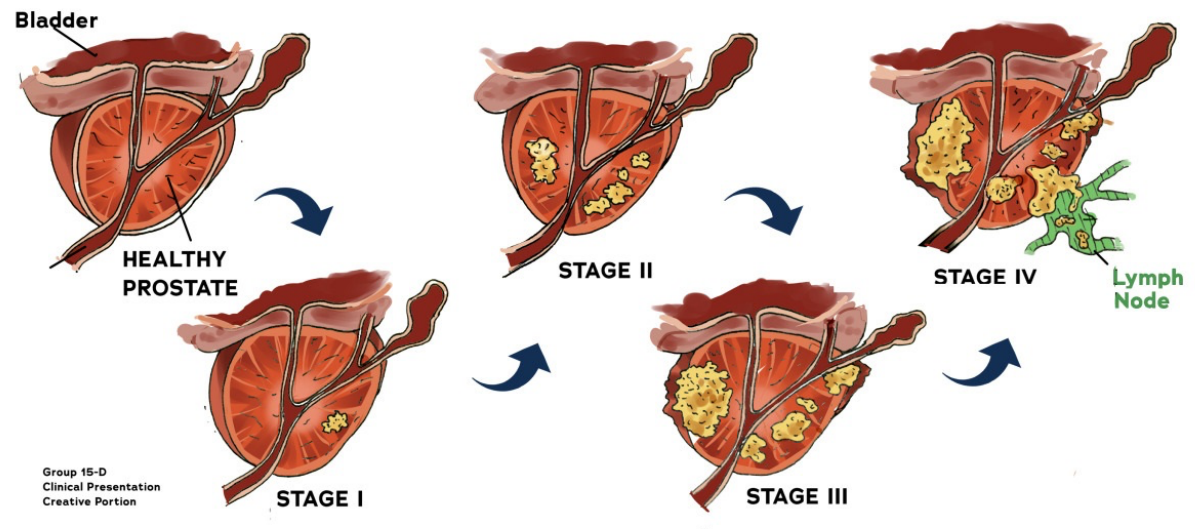

Artist Statement: 1 in 7 men will be diagnosed with prostate cancer in his lifetime. Prostate cancer can affect lymph flow, the colon, and ureter, causing symptoms such as urinary trouble, back pain and more. This schematic drawing of the Male Reproductive System could be used in a physician's office to aid explanation of this common disease.

\section{(1) (1)(2)}

This work is licensed under a Creative Commons Attribution-NonCommercialShareAlike 4.0 International License 


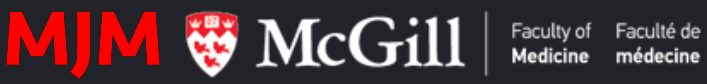

(c) McGill Journal of Medicine 2020

Electronic ISSN 1715-8125

\section{fE}

